\title{
Endoscopic ultrasound-guided choledochoduodenostomy (EUS-CDS) using electro- cautery-enhanced lumen-apposing metal stent: the easiest way to perform EUS-CDS?
}

Endoscopic ultrasound (EUS)-guided biliary drainage is an alternative to percutaneous transhepatic biliary drainage (PTBD) in patients with malignant biliary obstructions and those for whom endoscopic retrograde cholangiopancrea- tography (ERCP) fails or is impossible. Duodenal stenosis attributable to tumor overgrowth is a classic example of the latter situation. Although increasing evidence indicates that EUS-guided biliary drainage is superior to PTBD [1], only a

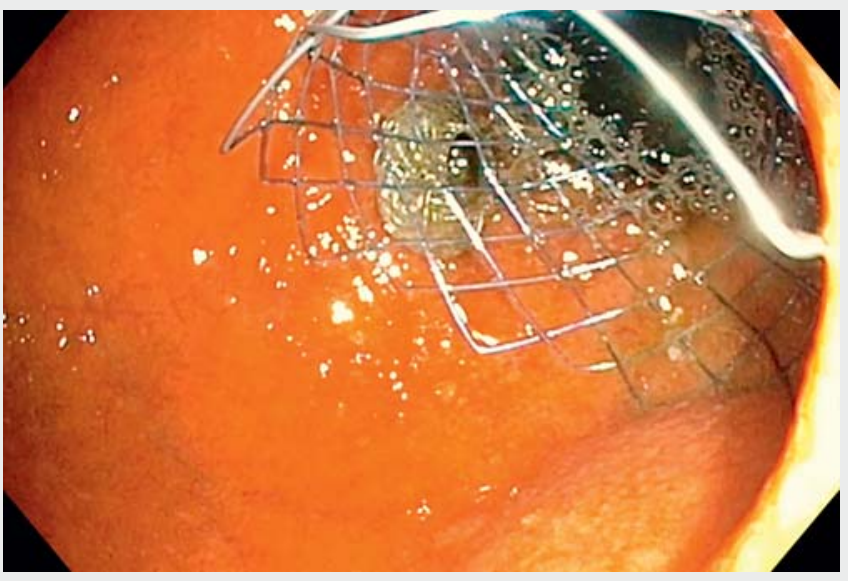

Video 1 Endoscopic ultrasound-guided choledochoduodenstomy with electrocauteryassisted placement of a lumen-apposing metal stent (AXIOS) and duodenal stent. few expert centers routinely perform the former procedure, which is technically challenging.

Recently, new lumen-apposing metal stents (LAMS) placed via electrocautery have become available; these can be used to aid EUS-guided choledochoduodenostomy (EUS-CDS). These all-in-one devices facilitate fast, safe EUS-CDS without the need for device exchange [2]. Here, we report the case of a 60 -year-old man with duodenal and biliary obstructions secondary to pancreatic head cancer ( Fig. 1 a).

The dilated bile duct was easily visualized close to the duodenal bulb using an endoscope placed via the conventional long route ( $\triangleright$ Fig.1 b). After direct puncture of the bile duct using the electrocautery device (AXIOS System; Boston Scientific, Marlborough, Massachusetts, USA), the sheath was pushed toward the opposite wall of the bile duct for correct positioning of the LAMS ( $6 \mathrm{~mm}$ diameter) ( $\triangleright$ Fig. 1 c). After locking the sheath, the distal flange was opened under EUS guidance
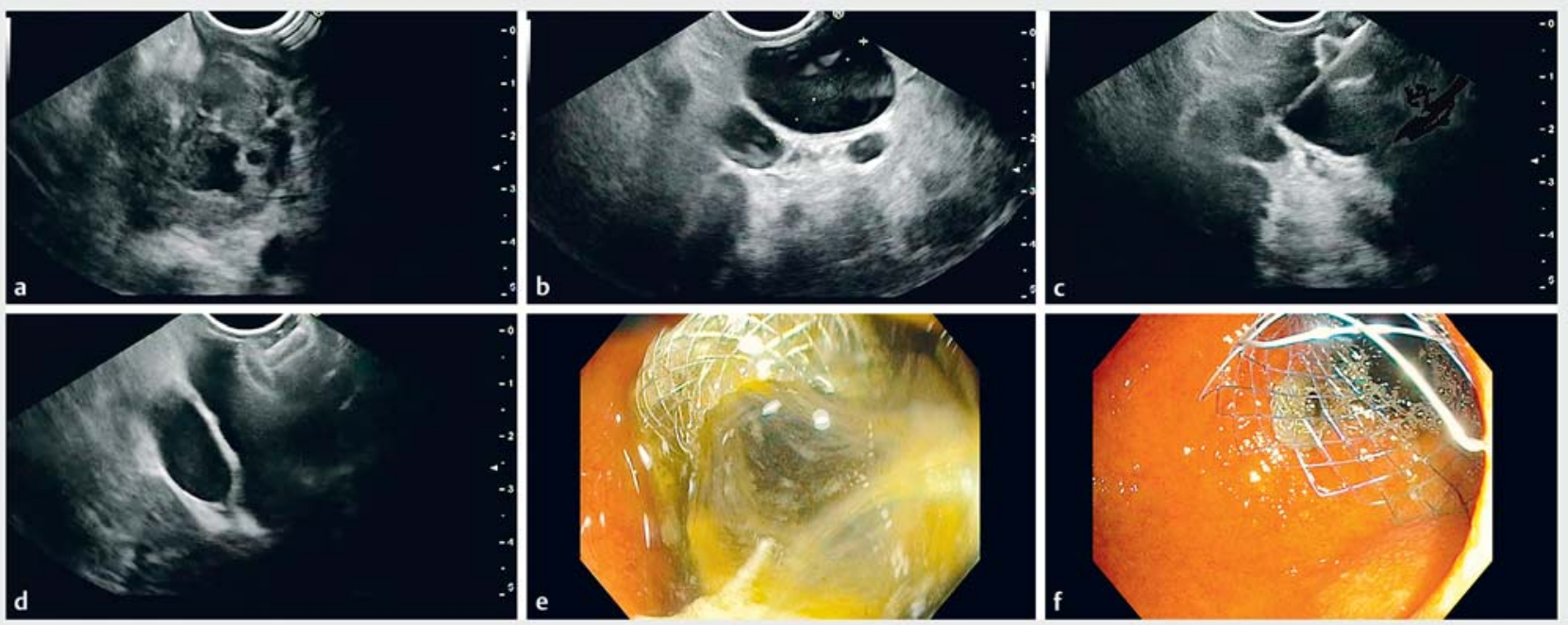

- Fig. 1 Endoscopic ultrasound (EUS) and endoscopic views of stent placement for duodenal and biliary obstructions secondary to pancreatic head cancer. a Pancreatic head cancer. b Dilated main bile duct. c Opening of the distal flange of the lumen-apposing metal stent (LAMS). d EUS view of the deployed LAMS. e Endoscopic view of the stent. $\mathbf{f}$ Choledochoduodenostomy and duodenal stent. 
using the dedicated stent deployment hub. The distal flange was deployed, then the sheath was gently removed until the distal flange became retracted and took a cone shape. Next, the proximal flange was deployed and the sheath was pushed to allow final stent deployment ( Fig.1d,e, $>$ Video 1). A classical duodenal stent was then deployed through the tumoral obstruction ( $\triangleright$ Fig. $1 \mathbf{f}$ ).

Four studies on EUS-CDS using the new device have already been published [2 5]. The technical and clinical success rates are very high. Morbidity seems to be much less than that associated with classical EUS-guided biliary drainage, probably because the absence of opacification and device exchange considerably reduces the risks of biliary leakage and cholangitis. This procedure may become the standard form of EUS-guided biliary drainage in patients with distal tumoral biliary obstructions in whom ERCP fails. The procedure is simple and safe, requiring only EUS guidance. No device exchange is required. The safety features incorporated into the device will render its use very popular.

Endoscopy_UCTN_Code_TTT_1AS_2AD

Competing interests

Dr. Jacques has been a speaker for Boston Scientific.
The authors

Marion Schaefer ${ }^{1,2}$, Jérémie Albouys ${ }^{2}$, Romain Legros $^{2}$, Denis Sautereau², Aurelie

Charissoux ${ }^{3}$, Hugo Lepetit ${ }^{2}$, Jeremie Jacques ${ }^{2,4}$

1 Service d'Hépato-gastro-entérologie, $\mathrm{CHU}$ de Nancy, Vandoeuvre-les-Nancy, France

2 Service d'Hépato-gastro-entérologie, $\mathrm{CHU}$ Dupuytren, Limoges, France

3 Service d'Anatomopathologie, CHU Dupuytren, Limoges, France

4 BioEM, UMR 7252, CNRS, Limoges, France

\section{Corresponding author}

\section{Marion Schaefer, MD}

Service d'Hépato-gastro-entérologie, CHU

de Nancy, Rue du Morvan, 54500

Vandoeuvre-les-Nancy, France

Fax: +33-3-83153633

mrn.schaefer@gmail.com

\section{References}

[1] Sportes A, Camus M, Greget M et al. Endoscopic ultrasound-guided hepaticogastrostomy versus percutaneous transhepatic drainage for malignant biliary obstruction after failed endoscopic retrograde cholangiopancreatography: a retrospective expertise-based study from two centers. Therap Adv Gastroenterol 2017; 10: 483 -493

[2] Jacques J, Privat J, Pinard F et al. Endoscopic ultrasound-guided choledochoduodenostomy with electrocautery-enhanced lumenapposing stents: a retrospective analysis. Endoscopy 2018. doi:10.1055/a-0735-9137
[3] Anderloni A, Fugazza A, Troncone E et al. Single-stage EUS-guided choledochoduodenostomy using a lumen-apposing metal stent for malignant distal biliary obstruction. Gastrointest Endosc 2018. doi:10.1016/j.gie.2018.08.047

[4] Kunda R, Pérez-Miranda M, Will U et al. EUS-guided choledochoduodenostomy for malignant distal biliary obstruction using a lumen-apposing fully covered metal stent after failed ERCP. Surg Endosc 2016; 30: 5002-5008

[5] Tsuchiya T, Teoh AYB, Itoi T et al. Long-term outcomes of EUS-guided choledochoduodenostomy using a lumen-apposing metal stent for malignant distal biliary obstruction: a prospective multicenter study. Gastrointest Endosc 2018; 87: 1138-1146

\section{Bibliography}

DOI https://doi.org/10.1055/a-0885-9196

Published online: 30.4.2019

Endoscopy 2019; 51: E219-E220

(C) Georg Thieme Verlag KG

Stuttgart · New York

ISSN 0013-726X

ENDOSCOPY E-VIDEOS
https://eref.thieme.de/e-videos
endoscopy. All papers include a high
quality video and all contributions are
freely accessible online.
This section has its own submission
website at
https://mc.manuscriptcentral.com/e-videos

